\title{
A Supramolecular Heat-Pump: an Electrochemical Cooling System Utilizing the Enthalpy Change of a Host-Guest Interaction
}

\section{Fumitoshi Matoba}

Kyushu University

Teppei Yamada ( $\nabla$ teppei@chem.s.u-tokyo.ac.jp )

The University of Tokyo

Nobuo Kimizuka

Kyushu University https://orcid.org/0000-0001-8527-151X

\section{Article}

Keywords: electrochemical Peltier effect, supramolecular heat-pump

Posted Date: July 1st, 2021

DOl: https://doi.org/10.21203/rs.3.rs-654324/v1

License: (c) (i) This work is licensed under a Creative Commons Attribution 4.0 International License.

Read Full License 


\section{Title}

A Supramolecular Heat-Pump: an Electrochemical Cooling System Utilizing the Enthalpy Change of a Host-Guest Interaction

\section{Author name}

Fumitoshi Matoba, ${ }^{1}$ Teppei Yamada, ${ }^{* 2}$ and Nobuo Kimizuka ${ }^{1,3}$

1 Chemistry and Biochemistry Course, Department of Applied Chemistry, Graduate School of Engineering, Kyushu University, Motooka 744, Nishi-ku, Fukuoka 819-0395, Japan.

2 Department of Chemistry, Graduate School of Science, The University of Tokyo, 7-3-1 Hongo, Bunkyo-ku, Tokyo 113-0033, Japan

${ }^{3}$ Center for Molecular Systems(CMS), Kyushu University

E-mail: teppei@chem.s.u-tokyo.ac.jp

Keywords: Electrochemical Peltier effect $\mid$ Host-guest chemistry | Cyclodextrin 


\begin{abstract}
Redox-stimulated host-guest chemistry was applied for the electrochemical Peltier effect, which is a heat transportation phenomenon observed in redox-active electrolytes. The refrigeration capability was enhanced up to $70 \%$. By the addition of alpha-Cyclodextrin ( $\alpha-\mathrm{CD})$ into $\mathrm{I}^{-} / \mathrm{I}_{3}{ }^{-}$aqueous solution, the amount of heat transported from the cathode side to the anode side was observed. The enhancement of the heat transportation was derived from the elimination heat of $\mathrm{I}_{3}{ }^{-}$from $\alpha$-CD associated with the shift of host-guest equilibrium caused by the exhausting of $\mathrm{I}_{3}{ }^{-}$by the reduction. This is the first report that utilized the stimuli-responsive supramolecular interaction for heat transportation.
\end{abstract}

\title{
Introduction
}

Refrigeration technology is of vital importance to our society that consumes more than $25 \%$ of the world's electricity ${ }^{[1]}$. Hence, novel refrigeration technologies are intensely investigated, such as magneto-dependent refrigeration ${ }^{[2][3][4]}$, pressure-driven refrigeration based on phase transition of plastic crystals ${ }^{[5][6]}$, and encapsulation-induced liquid-gas phase transition of gaseous molecule in elastic nanoporous carbon. ${ }^{[7]}$ Among these approaches, liquid media is advantageous for heat transportation, while a sophisticated liquid system needs to be developed to improve performance. As the alternative liquid heat-transportation technology, we propose herein to integrate with stimuliresponsive supramolecular chemistry.

Supramolecular chemistry makes the most of intermolecular interactions and molecular self- 
assembly, especially based on specific molecular recognition processes. ${ }^{[8]}$ So far, extensive studies have focused on the switching of molecular functions which are responsive to external stimuli. Shinkai and coworkers reported reversible capture and release of alkali cations by external light. ${ }^{[9]}$ Feringha and coworkers fabricated unidirectional molecular motors driven by heat and light. ${ }^{[10][11]}$ Stoddart and coworkers developed artificial molecular muscles, which can be contracted or extended in response to redox reactions. ${ }^{[12]}$ However, there have been no molecular systems capable of controlling heat changes by harnessing stimuli-responsive non-covalent interactions.

In this work, we demonstrate the first example of a supramolecular heat-pump system, which transports heat as latent heat of host-guest interactions in response to the redox reaction of iodide/triiodide $\left(\mathrm{I}^{-} / \mathrm{I}_{3}^{-}\right)$species. This system is based on the phenomenon called the electrochemical Peltier effect (EPE). EPE is a thermal effect that exhibits absorption or generation of heat at each electrode when an electric current flows through an electrochemical cell. The temperature changes in these systems take advantage of the reaction heat caused by the redox reaction. It has been reported that the redox couple of iodide/triiodide $\left(\mathrm{I}^{-} / \mathrm{I}_{3}^{-}\right)$show $\mathrm{EPE}{ }^{[13]}$. When the electrical current is applied into the aqueous $\mathrm{I}^{-} / \mathrm{I}_{3}^{-}$electrolyte, an exothermic oxidation reaction $\left(\mathrm{I}^{-}+2 \mathrm{e}^{-} \rightarrow \mathrm{I}_{3}{ }^{-}\right)$involving a decrease of entropy occurs at the anode side, while an endothermic reduction $\left(\mathrm{I}_{3}^{-} \rightarrow \mathrm{I}^{-}+2 \mathrm{e}^{-}\right)$with increasing entropy happens at cathode side (Fig. 1(a) ). Since the first report in 19th century ${ }^{[14]}$, EPE is studied to evaluate the reaction entropy of some redox couples such as $\left[\mathrm{Fe}(\mathrm{CN})_{6}\right]^{4-}$ 
$/\left[\mathrm{Fe}(\mathrm{CN})_{6}\right]^{3-[15][16][17][18]}, \mathrm{Cu} / \mathrm{Cu}^{2+[19][16][20]}$, and $\mathrm{I}^{-} / \mathrm{I}_{3}{ }^{-[13]}$. Because endothermic reaction occurs at one of the electrodes, EPE is potentially applicable to refrigeration. In 2019, Majumdar and coworkers demonstrated that the EPE of $\left[\mathrm{Fe}(\mathrm{CN})_{6}\right]^{4-3-}$ can be applied to refrigeration ${ }^{[21]}$. For further development of the electrochemical Peltier refrigeration system, it is imperative to develop strategies to enhance the amount of heat involving with redox reactions. In this work, we combined a host-guest interaction with a redox reaction to enhance EPE. $\alpha$-Cyclodextrin $(\alpha-C D)$ is a six-membered ring of glucose unit connected by $\alpha-1,4$-glycosidic bonds. The inner cavity of $\alpha$-CD is hydrophobic and forms an inclusion complex with hydrophobic molecules. $\mathrm{I}_{3}{ }^{-}$shows host-guest interaction with $\alpha$-CD and redox-active. The association reaction is promoted by increasing the concentration of free guest molecules, and vice versa. Hence, the host-guest interactions of redox-active guests can be evoked by the external electrical current input in electrochemical cells. Since association and dissociation reactions are exoand endo-thermic, respectively, the degree of heat changes associated with redox reactions will be enhanced (Fig. 1 (b)). In this report, we utilize the host-guest interaction between $\alpha$-CD and $\mathrm{I}_{3}{ }^{-}$to the EPE system and found the enhancement of the heat-transport performance by $70 \%$ due to the enthalpy change. This is the first report to apply supramolecular interactions for the heat transportation. 
a

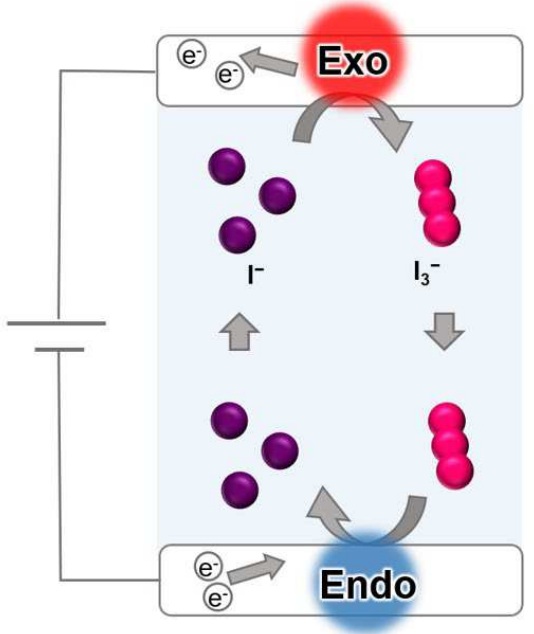

b

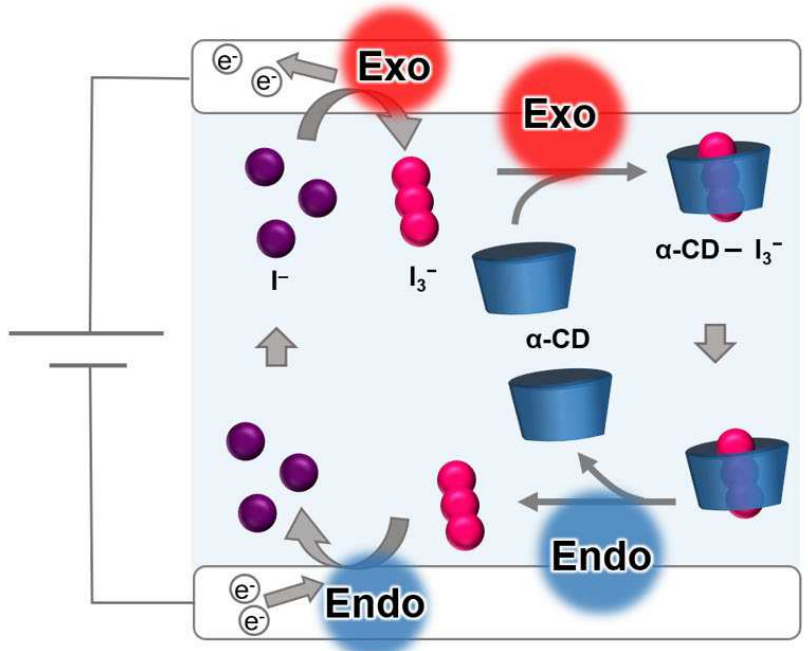

Figure 1. Schematic illustration of the electrochemical Peltier effect enhanced by supramolecular chemistry. (a) a conventional system based on the redox reaction of $\mathrm{I}^{-} / \mathrm{I}_{3}{ }^{-}$. By the external current input, the cathode side was cooled by the reduction of $/ \mathrm{I}_{3}{ }^{-}$to $3 \mathrm{I}^{-}$ions. An inverse reaction happens at the anode side with generating heat. (b) supramolecular system based on host-guest interaction between $\alpha-\mathrm{CD}$ and $\mathrm{I}_{3}{ }^{-}$. With the external current input, $\mathrm{I}_{3}{ }^{-}$was dessociated from $\alpha-\mathrm{CD}$ and attracts additional heat at the cathode side. At the anode side, the $\mathrm{I}_{3}{ }^{-}$was generated by the oxidation of $\mathrm{I}^{-}$, and additional heat was generated.

\section{Methods}

Electrolyte solution of $\mathrm{KI} / \mathrm{KI}_{3}$ and $\alpha-\mathrm{CD}$

$\mathrm{I}_{2}$ and $\alpha$-cyclodextrin were purchased from Wako Pure Chemical Industries (Japan). KI was purchased from Kishida Co. Ltd. (Japan). All reagents were used without any further purification.

Solution 1 was prepared by dissolving $\mathrm{KI}$ and $\mathrm{I}_{2}$ into water $\left(\left[\mathrm{KI}_{3}\right]=2.5 \mathrm{mM},[\mathrm{KI}]=10 \mathrm{mM}\right)$. Aqueous solution 2 was prepared by the addition of $\alpha$-CD into solution $1\left(\left[\mathrm{KI}_{3}\right]=2.5 \mathrm{mM},[\mathrm{KI}]=10 \mathrm{mM},[\alpha-\right.$ $\mathrm{CD}]=4 \mathrm{mM})$. Solution 3 was prepared by dissolving $\mathrm{KI}, \mathrm{I}_{2}, \alpha-\mathrm{CD}$, and $\mathrm{KNO}_{3}$ into water $\left(\left[\mathrm{KI}_{3}\right]=2.5\right.$ 
$\left.\mathrm{mM},[\mathrm{KI}]=10 \mathrm{mM},[\alpha-\mathrm{CD}]=4 \mathrm{mM},\left[\mathrm{KNO}_{3}\right]=100 \mathrm{mM}\right)$.

\section{Electrochemical Peltier measurement}

Electrochemical Peltier measurements were executed with house-made measurement apparatus consisting of two source meters (Keithley 2401), thermistor (SEMITEC 104JT-025), and thermostat (EC FRONTIER AC200). The electrochemical Peltier cell we designed and fabricated is shown in Fig.

S1.

The cell consists of PEEK resin and platinum plates $\left(0.5 \times 15 \times 15 \mathrm{~mm}^{3}\right)$. No reference electrode was used. The PEEK resin was polished with two types of polishing films (\# 4000 and \# 8000) before use. The platinum plate was immersed in concentrated sulfuric acid until just before use and polished with two types of polishing films (\# 4000, and \# 8000).

A cell was fabricated using $900 \mu \mathrm{L}$ of the electrolyte. The cavity $\left(1 \times 1 \times 1 \mathrm{~cm}^{3}\right)$ of the PEEK resin was filled with the electrolyte, and two platinum plates were bonded to the resin with Alardite.

Gold wires $(50 \mu \mathrm{m} \varphi)$ were attached to both electrodes using copper tape and connected to a source meter (Keithley 2401).

The temperature was measured with a sheet-type thermistor (SEMITEC 104JT-025). $1 \mu \mathrm{A}$ current was applied to the thermistor every 0.2 seconds, and the temperature was calculated from the resistance of the thermistor. The effect of the self-heating of the thermistor was negligible due to the small current value applied to the thermistor. 
The holder consists of a holder body made by a 3D printer and silicone rubbers. The electrodes and the thermistor were physically contacted by a screw penetrating the holder so that the temperature change of the electrode was transmitted to the thermistor (Fig. S1 (c)).

The measurement was performed by switching the direction of the current at regular intervals. Electrical current input and temperature recording were conducted simultaneously. The device was placed in a thermostat chamber (EC FRONTIER AC200) and the temperature was kept constant at 25 $\pm 1{ }^{\circ} \mathrm{C}$ during all the measurements.

\section{Cyclic voltammetry}

To evaluate the dissociation rate constant of $\mathrm{I}_{3}{ }^{-}$from $\alpha$-CD at the cathode side (Fig. S2), cyclic voltammetry was conducted with ALS 620D electrochemical analyzer (BAS). A glassy carbon $(\varphi=3$ $\mathrm{mm}$ ), platinum wire, and $\mathrm{Ag} / \mathrm{AgCl}$ electrode were used as the working, the counter, and the reference electrodes, respectively. Nitrogen bubbling was performed for 15 minutes before the measurement. The aqueous solution containing $\mathrm{KI}(4 \mathrm{mM}), \mathrm{I}_{2}(1 \mathrm{mM}), \alpha-\mathrm{CD}(10 \mathrm{mM})$, and $\mathrm{KNO}_{3}(100 \mathrm{mM})$ was used, and the temperature was kept at $25^{\circ} \mathrm{C}$.

\section{Ionic conductivity and thermal conductivity}

To evaluate the $Z$ value shown in Eqn(7), ionic conductivity and thermal conductivity were determined.

The ionic conductivity of the electrolyte at room temperature was measured by a portable electric 
conductivity meter (ES-71, HORIBA) using a sample solution in a $50 \mathrm{~mL}$ vial with a standard procedure. The thermal conductivity of the electrolyte was measured by a hot disk thermal constants analyzer (HOT DISK TPS500, Kyoto Electronics, Japan) with a 7577 probe at room temperature according to the previous report. ${ }^{[1]}$ The measurement was repeated more than five times.

\section{Results and Discussions}

To experimentally observe EPE, we fabricated a measurement cell and monitored the temperature changes caused by the redox reactions in the vicinity of the electrodes (Fig. 2(a) and S1). A rectangular alternating current with constant frequency was applied to the cell. As widely reported in other cooling effects ${ }^{[4][19][20][22] ~[23], ~ e l e c t r o c h e m i c a l ~ P e l t i e r ~ h e a t i n g / c o o l i n g ~ a n d ~ J o u l e ~ h e a t i n g ~ c a n ~ b e ~ s e p a r a t e d ~ b y ~}$ applying the alternating current. This is because the former effect is a reversible thermodynamic process that depends linearly on the current $(\propto I)$ and has the same frequency as applied current, whereas the latter is an irreversible process that exhibits a quadratic response to the current $\left(\propto I^{2}\right)$. In order to obtain precise thermal responses, the alternating current was applied for more than one thousand periods, and the observed temperature changes were averaged.

Fig. 2(b) and Fig. 2(c) show the average temperature changes that reflect the reduction and oxidation reactions when $0.15 \mathrm{~mA}$ current was applied to the cell. The average temperature decreased linearly with reduction, then increased with oxidation. The anodic reaction is associated with the oxidation of 
$\mathrm{I}^{-}$to $\mathrm{I}_{3}{ }^{-}$, which is previously reported as an exothermic reaction. ${ }^{[13]}$ Since the oxidation reaction is accompanied by a decrease in the number of molecules or entropy near the electrode, the oxidation reaction is exothermic and vice versa. By the addition of $\alpha-\mathrm{CD}$, the temperature changes with oxidation and reduction were enhanced, which indicates that EPE was enhanced by the host-guest interaction (Fig. 2(c)). With the anodic current, $\mathrm{I}_{3}{ }^{-}$species was generated and was captured by $\alpha$-CD that released the heat. On the other hand, the cathodic current decreases the $\mathrm{I}_{3}{ }^{-}$concentration, which promotes the dissociation of $\mathrm{I}_{3}{ }^{-}$from $\alpha-\mathrm{CD}$ and deprives the heat. The $\alpha-\mathrm{CD}-\mathrm{I}_{3}{ }^{-}$complex generated at the anode side is transferred to the bulk, and the consumed $\alpha-\mathrm{CD}-\mathrm{I}_{3}{ }^{-}$at the cathode side is supplied from the bulk by diffusion: thus continuous heat transportation was achieved. As a result, $\alpha$-CD transfers heat from the cold to the hot side as latent heat of host-guest interaction in response to the electrical current input.

The quantitative effect of the host-guest interaction on the EPE was evaluated. In this system, we assumed that Joule heating, electrochemical Peltier heat, and thermal conduction are the main three factors. Electrochemical Peltier coefficient $(\Pi)$ is usually the amount of heat with reversible redox reaction $(\Pi=T \Delta S)$. Although the electrical current input is an irreversible redox reaction process, we assumed that the amount of heat is kept the same as the electrochemical Peltier coefficient regardless of the current value. The temperature change of the electrode associated with oxidation $\left(T_{\mathrm{ox}}(\mathrm{t})\right)$ and reduction $\left(T_{\text {red }}(\mathrm{t})\right)$ are expressed as below equations. 


$$
\begin{aligned}
T_{o x}(t) & =\frac{a R I^{2}}{C} t+\left(T_{o x}(0)-T_{0}-\frac{\Pi}{2 n F K}|I|\right) \exp \left(-\frac{2 K}{C} t\right)+T_{0}+\frac{\Pi}{2 n F K}|I| \\
T_{\text {red }}(t) & =\frac{a R I^{2}}{C} t+\left(T_{\text {red }}(0)-T_{0}+\frac{\Pi}{2 n F K}|I|\right) \exp \left(-\frac{2 K}{C} t\right)+T_{0}-\frac{\Pi}{2 n F K}|I|
\end{aligned}
$$

where $t$ is time (sec), $I$ is current (A), $R$ is electric resistance $(\Omega), a$ is the ratio of Joule heat generated at the electrode to the total Joule heat. $C$ is the cell constant $\left(\mathrm{J} \mathrm{K}^{-1}\right), T_{0}$ is the electrode temperature (K) when no current is input, $\Pi$ is an electrochemical Peltier coefficient $\left(\mathrm{J} \mathrm{mol}^{-1}\right) . n$ is the number of electrons in the redox reaction, $F$ is Faraday's constant $\left(\mathrm{C} \mathrm{mol}^{-1}\right)$, and $K$ is the thermal conductance $\left(\mathrm{W} \mathrm{K}^{-1}\right)$. More detailed explanations are provided in Supporting Information. In this report, the linear temperature change was observed because the applied current is small enough, and the effect of the thermal conduction can be ignored. In this case, Eqn(1) and Eqn(2) can be rewritten as below:

$$
\begin{aligned}
& T_{o x}(t)=\frac{a R I^{2}}{C} t+T_{0}+\frac{\Pi}{2 n F K}|I| \\
& T_{\text {red }}(t)=\frac{a R I^{2}}{C} t+T_{0}-\frac{\Pi}{2 n F K}|I|
\end{aligned}
$$

Based on Eqn (3) and Eqn (4), the effect of Joule heating can be expired by taking the difference of these temperatures, as expressed by equation (5),

$$
T_{o x}(t)-T_{\text {red }}(t)=\frac{2 \Pi|I|}{n F C} t+\left\{T_{o x}(0)-T_{\text {red }}(0)\right\}
$$

Fig. 2 (d), (e) shows the $T_{o x}(t)-T_{\text {red }}(t)$ plot against time. By introducing $\alpha-C D$, the slope was increased by $c a .1 .7$ times from $0.78 \times 10^{-1} \mathrm{mK} \mathrm{sec}{ }^{-1}$ to $1.3 \times 10^{-1} \mathrm{mK} \mathrm{sec}{ }^{-1}$, which means that the electrochemical Peltier coefficient $(I)$ increased by 1.7 times by the addition of $\alpha$-CD. It should be noted that $2 \Pi / n F C$ values calculated from the slopes of $T_{\text {ox }}(\mathrm{t})-T_{\text {red }}(\mathrm{t})$ plots were almost constant when 
the current value does not exceed $0.15 \mathrm{~mA}$ (Fig S7), which indicates the validity of the assumption that $\Pi$ value is constant in this current range. 


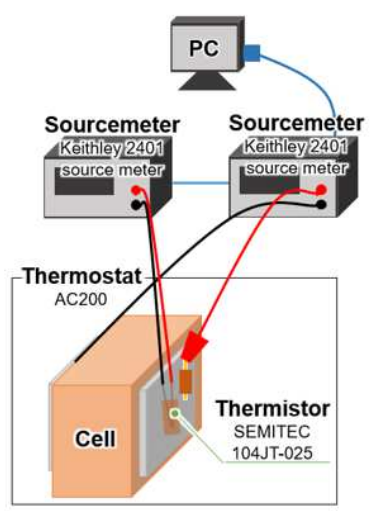

b

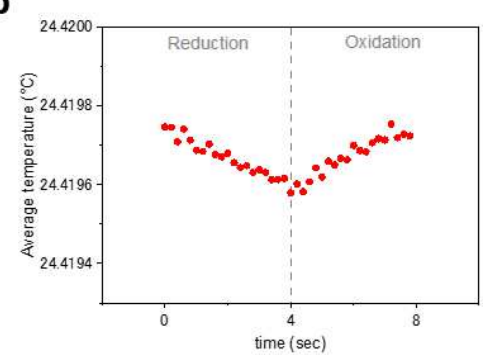

C

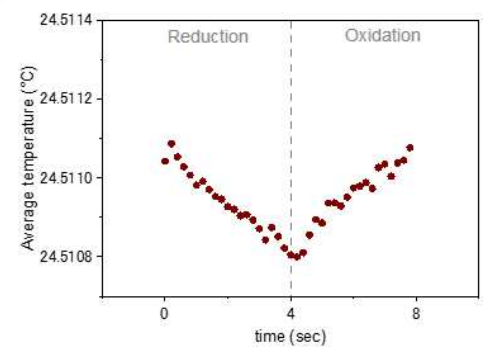

d

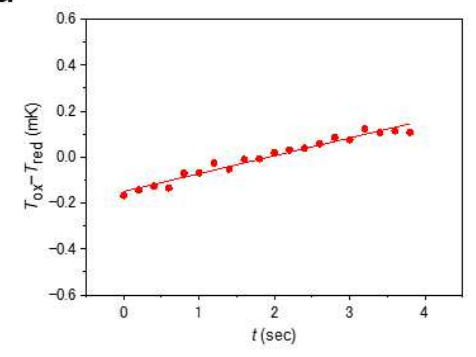

e

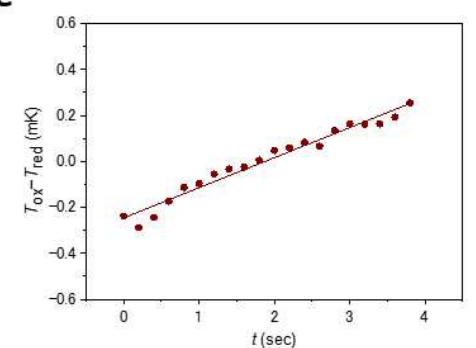

Figure 2. Electrochemical Peltier measurement. (a) Schematic illustration of the experimental setup. The external current was applied from a source meter and the temperature of the vicinity of the electrode was monitored. For the measurement, $\pm 0.15 \mathrm{~mA}$ current was applied, and the direction was reversed every 4 seconds. The reduction and oxidation cycles were repeated 4999 times, and the observed temperature was averaged. (b) The average temperature change of an electrode without $\alpha$ CD. (c) The average temperature change of an electrode with $\alpha-\mathrm{CD}$. The electrolytes are (b) $[\mathrm{KI}]=$ $10 \mathrm{mM},\left[\mathrm{KI}_{3}\right]=2.5 \mathrm{mM}$; (c) $[\mathrm{KI}]=10 \mathrm{mM},\left[\mathrm{KI}_{3}\right]=2.5 \mathrm{mM},[\alpha-\mathrm{CD}]=4 \mathrm{mM}$. (d, e) Relationship between $T_{\text {ox }}(\mathrm{t})-T_{\text {red }}(\mathrm{t})$ against $t$ of (b) and (c), respectively. The slope of the plots is proportional to the electrochemical Peltier constants.

The origin of enhancement was discussed. According to Onsager's reciprocal principle, the electrochemical Peltier coefficient $(\Pi)$ is proportional to the Seebeck coefficient $\left(S_{\mathrm{e}}\right)$.

$$
\Pi=n F T S_{e}
$$

where Seebeck coefficient is the potential difference $(\Delta V)$ generated by a given temperature gradient $(\Delta T)$, which is expressed as $S_{\mathrm{e}}=\Delta V / \Delta T$. In the field of thermocell, it is already investigated that the Seebeck coefficient increases $c a$. 1.7 times from $0.86 \mathrm{mV} \mathrm{K}^{-1}$ to $1.45 \mathrm{mV} \mathrm{K}^{-1}$ by the addition of $\alpha$ $\mathrm{CD}^{[24]}$, which is in good agreement with the enhancement of electrochemical Peltier coefficients by 1.7 times. 
Based on Eqn (2), the electrochemical Peltier coefficient of the $\mathrm{I}^{-} / \mathrm{I}_{3}{ }^{-}$solution is estimated as $49.5 \mathrm{~kJ}$ $\mathrm{mol}^{-1}$ at $25{ }^{\circ} \mathrm{C}$. In the previous report, the enthalpy change of association between $\alpha-\mathrm{CD}$ and $\mathrm{I}_{3}{ }^{-}$was estimated as $50.3 \mathrm{~kJ} \mathrm{~mol}^{-1}$ by isothermal titration calorimetry (ITC) measurement. ${ }^{[24]}$ Since the association constant between $\alpha$ - $\mathrm{CD}$ and $\mathrm{I}_{3}{ }^{-}$is over $1 \times 10^{5} \mathrm{M}^{-1}$ at room temperature ${ }^{[24]}$, almost all $\mathrm{I}_{3}{ }^{-}$ in the bulk forms inclusion complex with $\alpha-\mathrm{CD}$. Therefore, it is expected that about $70 \%$ of association enthalpy change contributed to the enhancement. We expect that the enthalpy change of the rest $30 \%$ dissipated into the electrolyte or solution because the host-guest interaction occurs slightly away from the redox reaction site that occurs close to the electrode/electrolyte interface. 


\section{Maximum temperature difference}

The temperature difference between electrodes is one of the important parameters for evaluating cooling performance. A maximum temperature difference $\left(\Delta T_{\max }\right)$ is defined to the temperature difference when the cold side is at the lowest temperature, and it can be obtained when the constant voltage $V=S_{\mathrm{e}} T_{\mathrm{c}}$ is applied into the cell (See SI). Fig. 3 shows the average temperature change of the electrode when the rectangular alternating voltage corresponding to $|V|=S_{\mathrm{e}} T_{\mathrm{c}}$ was applied to the cell. The sign of the voltage was changed every 40 seconds for 1000 cycles. As shown in the figure, the temperature difference was gradually increased and converged to a constant value at each condition. Without $\alpha-\mathrm{CD}, \Delta T_{\max }$ was $c a .0 .8 \mathrm{mK}$. On the other hand, with the $4 \mathrm{mM}$ of $\alpha-\mathrm{CD}, \Delta T_{\max }$ was enhanced to $c a .1 .0 \mathrm{mK}$.

$\Delta T_{\max }$ can be expressed as Eqn (7),

$$
\Delta T_{\max }=\frac{1}{2} \frac{\sigma S_{e}^{2}}{\kappa} T_{c}^{2}=\frac{1}{2} Z T_{c}^{2}
$$

where $\sigma$ is the electrical conductivity, $\kappa$ is the thermal conductivity, and $Z$ is called the figure of merit. Theoretical $\Delta T_{\max }$ value in the absence and presence of $\alpha-\mathrm{CD}$ was calculated as $8.7 \mathrm{mK}$ and $23 \mathrm{mK}$, respectively (see SI). The observed values are one order of magnitude smaller than theoretical values. This indicates that the heat dissipated outside the cell since the cell was physically in contact with the clamping units and that the design of the cell could drastically improve the cooling ability. It is to note that, with the recent improvement of the $Z T$ value of electrolytes in the field of thermocells ${ }^{[25][26][27]}$, such as the use of high-surface-area electrodes ${ }^{[25]}$, the cooling ability of the EPE device could be 
largely improved. It is also to note that the EPE system enables the direct cooling of liquid by simple electrical current, and could be the alternative candidate for cooling devices. It is demonstrated that the host-guest chemistry can be a useful method for electrical cooling.

a

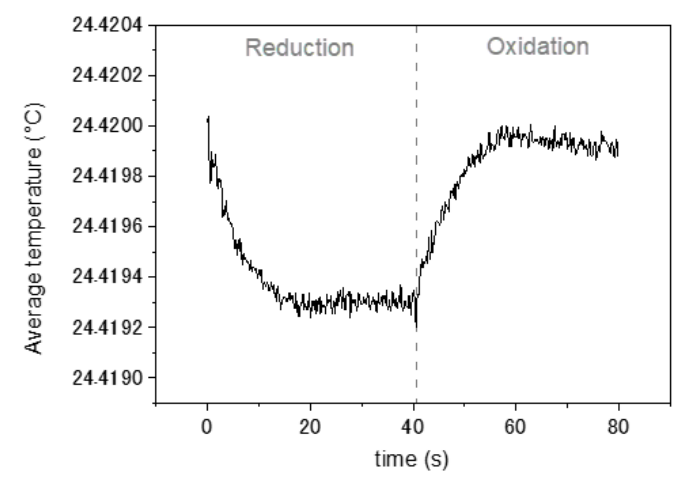

b

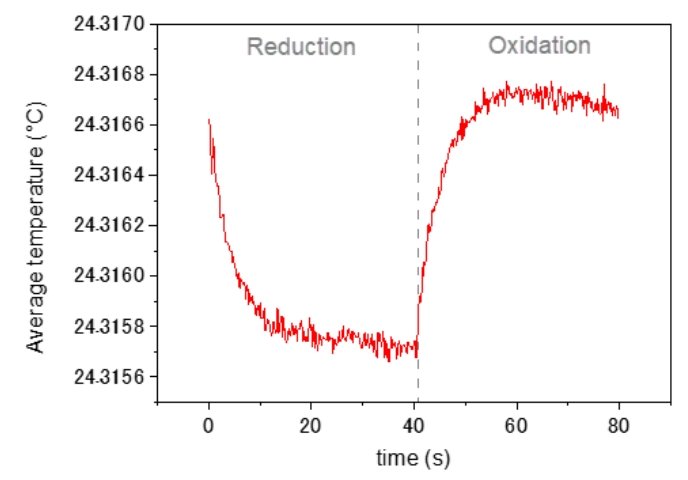

Figure 3. (a) Temperature change of an electrode without $\alpha$-CD (a) and with $\alpha$-CD (b). $\pm 0.26 \mathrm{~V}$ (a) and $\pm 0.43 \mathrm{~V}$ (b) were applied to the cell. The voltage direction was reversed every 40 seconds. The reduction and oxidation cycles were repeated 999 times, and the temperature was averaged. The electrolytes are (a) $[\mathrm{KI}]=10 \mathrm{mM},\left[\mathrm{KI}_{3}\right]=2.5 \mathrm{mM}$; (b) $[\mathrm{KI}]=10 \mathrm{mM},\left[\mathrm{KI}_{3}\right]=2.5 \mathrm{mM},[\alpha-\mathrm{CD}]=4$ $\mathrm{mM}$.

\section{Conclusion}

In summary, we report the first proof-of-concept of the refrigeration system based on supramolecular interaction. Host-guest interaction between $\alpha-\mathrm{CD}$ and $\mathrm{I}_{3}{ }^{-}$was electrochemically induced at each electrode, and the heat involving with association and dissociation distributed to the enhancement of EPE. By introducing $\alpha-\mathrm{CD}$ into an aqueous $\mathrm{I}^{-} / \mathrm{I}_{3}^{-}$solution, the amount of heat involved with the redox reaction was enhanced approximately by $70 \%$, which showed good agreement with the theoretical value. This work provides a new possibility of supramolecular chemistry as a heat transportation 
method.

\section{References}

[1] IIFIIR, 38th Note on Refrigeration Technologies: The Role of Refrigeration in the Global Economy, 2019.

[2] J. Flipse, F. L. Bakker, A. Slachter, F. K. Dejene, B. J. Van Wees, Nat. Nanotechnol. 2012, 7, $166-168$.

[3] K. Uchida, R. Iguchi, S. Daimon, R. Ramos, A. Anadón, I. Lucas, P. A. Algarabel, L. Morellón, M. H. Aguirre, M. R. Ibarra, et al., Phys. Rev. B 2017, 95, DOI 10.1103/PhysRevB.95.184437.

[4] K. I. Uchida, S. Daimon, R. Iguchi, E. Saitoh, Nature 2018, 558, 95-99.

[5] B. Li, Y. Kawakita, S. Ohira-Kawamura, T. Sugahara, H. Wang, J. Wang, Y. Chen, S. I. Kawaguchi, S. Kawaguchi, K. Ohara, et al., Nature 2019, 567, 506-510.

[6] P. Lloveras, A. Aznar, M. Barrio, P. Negrier, C. Popescu, A. Planes, L. Mañosa, A. Avramenko, N. D. Mathur, X. Moya, et al., Nat. Commun. n.d., 1-7.

[7] K. Nomura, H. Nishihara, M. Yamamoto, A. Gabe, M. Ito, M. Uchimura, Y. Nishina, H. Tanaka, M. T. Miyahara, T. Kyotani, Nat. Commun. 2019, 10, 1-10.

[8] J. M. Lehn, Pure Appl. Chem. 1978, 50, 871-892.

[9] S. Shinkai, T. Ogawa, T. Nakaji, Y. Kusano, O. Nanabe, Tetrahedron Lett. 1979, 20, 4569-4572.

[10] N. Koumura, R. W. J. Zijlstra, R. A. van Delden, N. Harada, B. L. Feringa, Nature 1999, 401, $152-155$.

[11] R. A. Van Delden, M. K. J. Ter Wiel, M. M. Pollard, J. Vicario, N. Koumura, B. L. Feringa, Nature 2005, 437, 1337-1340.

[12] Y. Liu, A. H. Flood, P. A. Bonvallet, S. A. Vignon, B. H. Northrop, H. R. Tseng, J. O. Jeppesen, T. J. Huang, B. Brough, M. Baller, et al., J. Am. Chem. Soc. 2005, 127, 9745-9759.

[13] P. Boudeville, Inorganica Chim. Acta 1994, 226, 69-78.

[14] E. J. Mills, Proc. R. Soc. London 1877, 26, 504.

[15] R. Tamamushi, J. Electroanal. Chem. 1975, 65, 263-273.

[16] P. Boudeville, A. Tallec, Thermochim. Acta 1988, 126, 221-234.

[17] F. Decker, M. Fracastoro-Decker, N. Cella, H. Vargas, Electrochim. Acta 1990, 35, 25-26.

[18] Z. Fang, S. Wang, Z. Zhang, G. Qiu, Thermochim. Acta 2008, 473, 40-44.

[19] R. Tamamushi, Electroanal. Chem. Interfacial Electrochem. 1973, 45, 500-503.

[20] T. Ozeki, N. Ogawa, K. Aikawa, I. Watanabe, S. Ikeda, J. Electroanal. Chem. 1983, 145, 53-65.

[21] I. S. McKay, L. Y. Kunz, A. Majumdar, Sci. Rep. 2019, 9, 1-8.

[22] J. Flipse, F. L. Bakker, A. Slachter, F. K. Dejene, B. J. Van Wees, Nat. Nanotechnol. 2012, 7, 
$166-168$.

[23] W. Jin, L. Liu, T. Yang, H. Shen, J. Zhu, W. Xu, S. Li, Q. Li, L. Chi, C. an Di, et al., Nat. Commun. 2018, 9, 1-6.

[24] H. Zhou, T. Yamada, N. Kimizuka, J. Am. Chem. Soc. 2016, 138, 10502-10507.

[25] H. Im, T. Kim, H. Song, J. Choi, J. S. Park, R. Ovalle-Robles, H. D. Yang, K. D. Kihm, R. H. Baughman, H. H. Lee, et al., Nat. Commun. 2016, 7, 1-9.

[26] J. H. Kim, J. H. Lee, R. R. Palem, M. S. Suh, H. H. Lee, T. J. Kang, Sci. Rep. 2019, 9, 1-8.

[27] B. Yu, J. Duan, H. Cong, W. Xie, R. Liu, X. Zhuang, H. Wang, B. Qi, M. Xu, Z. L. Wang, et al., Science (80-. ). 2020, 370, 342-346.

\section{Acknowledgments}

This work was partly supported by JST PRESTO Grant Number JPMJPR141D, JSPS KAKENHI Grant Numbers JP25220805, JP17H03046, JP21H00017, JP19H05061(Hydrogenomics), JP16H06513 (Coordination Asymmetry), JP21H00017, JP20K21176, JP20H02714, the Ogasawara Foundation for the Promotion of Science \& Engineering, The Thermal and Electric Energy Technology Foundation, The Asahi Glass Foundation, and Kurata Grants.

\section{Author contributions}

F. M. constructed the experimental setup, execute all experiments, produced the theoretical relationship, and wrote the manuscript. T. Y. designed the experiment, consulted the experiments and revised the manuscript. N. K. supervised the research and revised the manuscript.

\section{Competing Interests statement}

There is no competing interest to declare. 


\section{Supplementary Files}

This is a list of supplementary files associated with this preprint. Click to download.

- 210625supraEPESI.docx

- 210625supraEPESI.docx 